\title{
Design And Numerical Analysis of Morphing Airfoil With Corrugated Geometry In The Application MAV's
}

Kishore Kumar ( $\nabla$ ksandan@gitam.edu )

GITAM School of Technology https://orcid.org/0000-0003-0398-1935

Kanneti Nithisha

GITAM Institute of Technology

Manvi Vivek

GITAM Institute of Technology

Mohammad Saniya Simran

GITAM Institute of Technology

Ravi Sri Raman

GITAM Institute of Technology

\section{Research}

Keywords: Corrugation, Morphing, Turbulent models, RBF

Posted Date: November 16th, 2021

DOI: https://doi.org/10.21203/rs.3.rs-1066886/v1

License: (c) (1) This work is licensed under a Creative Commons Attribution 4.0 International License.

Read Full License 


\title{
Design and numerical analysis of morphing airfoil with corrugated geometry in the application MAV's
}

\author{
Mr. S. Kishore Kumar ${ }^{\star}$, Kanneti Nithisha ${ }^{2}$, Manvi Vivek ${ }^{3}$ and Mohammad Saniya Simran ${ }^{4}$, \\ Dr. Ravi Sri Raman ${ }^{5}$ \\ *Corresponding author \\ Email id's-ksandan@gitam.edu*
}

Department of Aerospace Engineering, GITAM School of Technology 1,2,3,4,5

Gitam University, Rudraram, Telangana 502329

\begin{abstract}
The main objective of the work is to enhance the aerodynamic performance during takeoff and cruise by using newly corrugated airfoil of MAV's by Morphing it at the trailing edge. In this study, the transient nature of corrugated airfoils at low Reynolds number were assumed to be the flow is laminar, incompressible and two dimensional. The newly corrugated geometry which is parameterized from the camber line using a Radial basis function (RBF) based on interpolation method positioned at the lower surface of the airfoil i.e., NACA0015. Five morphed geometries are designed using ANSYS Space claimer. The computational domain is meshed using cartesian grid, the surface meshes with quadrilateral. Numerical simulations are performed with turbulent models i.e., k-omega, k-epsilon and Spalart allmaras. In the analysis, there is an increment of coefficient of lift and decrease in coefficient of drag by varying Reynolds number. Compared to NACA0015, corrugated NACA0015 shows good results.
\end{abstract}

Keywords: Corrugation, Morphing, Turbulent models, RBF

\section{INTRODUCTION}

Micro Aerial Vehicle is a miniature of UAV's that has size restriction and maybe autonomous. The development of innovative adaptive structures on MAV's, such as "Morphing wings", can potentially reduce the complexity of the aviation structure. These are divided into Fixed wing MAVs, Rotary wing MAVs, Flapping wing MAVs. Fixed wing MAVs are aircraft models of size less than $200 \mathrm{~mm}$, controlled by remote. This can be as small as human palm. These MAVs have wing and propeller, helps them to fly.

Rotary wing MAVs are tiny helicopters, controlled by remote. They don't have wing they use rotors. These are most commonly used MAVs.

Flapping wing MAVs are most trending recent in the development of MAVs. These MAVs are most complicated then compared to other MAVs as they use the same mechanism as bird to achieve flight. As birds flap wing in different ways to achieve flight. Different birds have different ways to flap there wings, insects also have different ways to flap there wings. Now MAVs have been also designed by observing the dragonfly.

Modern craft can be as small as 5 centimetres. Most of the development of MAVs are seen for commercial, research, government and military purpose. The interest on Morphing wing has been increased due to its superior benefits. The structure that can change its geometric characteristics and also properties (stiffness and damping) according to the mission requirements or at different load conditions.[1] The main idea in positioning corrugated portion is for actuating the trailing edge. Besides, it will re-energies the flow which will helps to delay the flow from separation. The Maximum speed of a Micro Aerial vehicle would be around $10-15 \mathrm{~m} / \mathrm{s}$. As we are considering a low Reynolds number. Because the boundary layer is the great deal of managing an adverse pressure without separation. The assumptions we made for this study are the flow is laminar, steady, incompressible and 2-Dimensional. MAVs have the potential to operate the missions in denser regions that near the Earth surface. Near the earth surface the airflow is turbulent. This results in turbulent intensity on the stability of the MAVs. 
Most MAVs have problems during takeoff and cruise. As a result, main objective is to enhance the aerodynamics performance by using corrugated used for morphing the trailing edge. All the cases of MTE optimized airfoils have showed a significant improvement in the overall aerodynamic performance, and MTE airfoils increased the efficiency.

In this paper a computational study is done in order to investigate the aerodynamic performance of newly corrugated airfoil, positioned at $25 \%$ of the chord length from the trailing edge of the airfoil by continuously morphing trailing edge wing.

In order to increase the aerodynamic performance by morphing technology by placing corrugated design at the lower surface of the symmetric airfoil (i.e., NACA0015) and using by giving deflections of airfoil models (2deg, $5 \mathrm{deg}, 7 \mathrm{deg}$, $9 \mathrm{deg}$ ) at the trailing part of the airfoil. The airfoil is reconstructed from the camber line using a Radial Basis Function (RBF) based on interpolation method.

Performed the study by using the concept of different turbulence models (k-omega, k-epsilon and Spalart allmaras).[2]

All the three models were considered and used to analyse the newly designed aerofoil for MAVs.

Compared to all the models, k-epsilon model has interpreted the good results.

For MAVs, the wing must be flexible to cover a smooth configuration. Corrugated structure can undergo high aerodynamic loads and helps to morph the wing smoothly.[4]

\section{AIRFOIL OPTIMIZATION}

In order to model the airfoil, there is a method to be followed and to carry out the mesh deformation, calculate the aerodynamic coefficients and also attached the optimization models in the following sections.

\subsection{Parameterization}

To give the corrugated portion at lower portion of the NACA0015 airfoil, Radial Basis Function is used, explained as follows

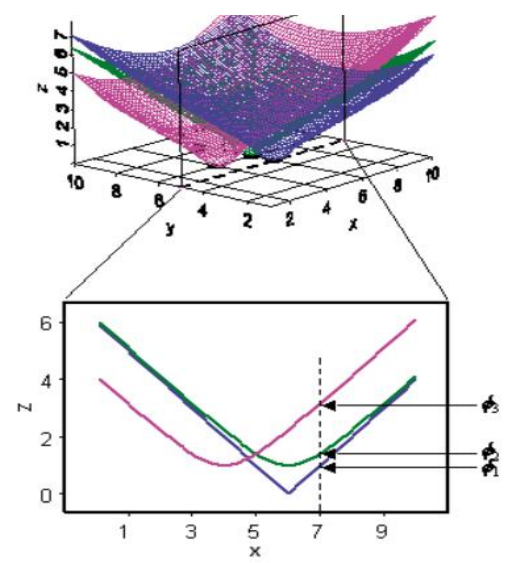

By using above figure, the values of Radial basis function at the predicted location can be considered, as given by $\Phi_{1}, \Phi_{2}$, and $\Phi_{3}$, it depends on the distance between the data location. The Predictor can be estimated by taking the weighted average $\mathbf{W}_{1} \Phi_{1}+\mathbf{W}_{2} \Phi_{2}+\mathbf{W}_{3} \Phi_{3}+\ldots$. There are different methods in it, they are ThinPlate spline, Spline with Tension, completely regularized spline, Multiquadric function, Inverse multiquadric function. Sometimes, they don't make greater difference.

In order to design the model, Firstly, the model dimensions are collected from NACA tools from NASA website. After, five models are modelled by giving 5 deflections $\left(0^{\circ}, 2^{0}, 5^{\circ}, 7^{\circ}, 9^{\circ}\right)$ at the trailing edge. To actuate the deflected portion a corrugated portion is positioned at $25 \%$ of chord of $150 \mathrm{~mm}$.

\subsection{Mesh deformation}

The computational domain was meshed by using Cartesian grids. To get accurate values, refinement is also given around the surface of the deflected air foil. 


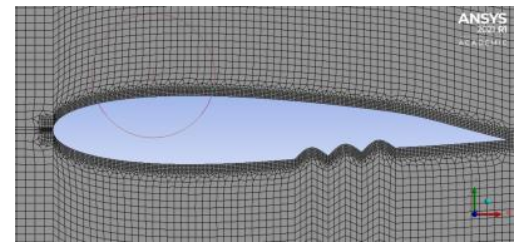

Fig-A Mesh deformation at $5^{0}$ deflection

\subsection{Flow Solver}

The analysis is done by using three turbulent models.

\section{Spalart-Allmaras model}

The One-Dimensional Spalart-Allmaras is an easy model that resolves a modelled transport equation for the kinematic eddy (turbulent) viscosity. This model is generally used for wall-bounded flows and has good outputs for boundary layer subjected to ambient pressure gradients.

In Spalart allmaras, the transported variable $\tilde{v}$ is similar to the turbulent kinematic viscosity except in the nearwall region.

$\left[\partial / \partial t(\rho \tilde{v})+\partial / \partial x i(\rho \tilde{v} u i)=G_{v}+1 / \sigma_{\tilde{v}}\left[\partial / \partial x i\{(\mu+\rho \tilde{v}) \partial \tilde{v} / \partial x i\}+C_{b_{2}} \rho(\partial \tilde{v} / \partial x i)^{2}\right]-Y_{v}+S_{\tilde{v}}\right] \quad \ldots \ldots . .$. eq -1

$G_{v}$ is the production of turbulent viscosity, $Y_{v}$ is the destruction of turbulent viscosity that happens in the near wall region because of the wall blocking and viscous damping, $\boldsymbol{\sigma} \tilde{\boldsymbol{v}}$ and $\boldsymbol{C b} \mathbf{2}$ are constants, v is the molecular kinematic viscosity and $\boldsymbol{S} \tilde{\boldsymbol{v}}$ is a user-defined source term.

Note: Turbulence kinetic energy is not calculated in Spalart-Allmaras model.

The production term $\boldsymbol{G}_{v}$ can be modelled has

$$
\left[G_{v}=C_{b 1} \rho \tilde{S} \tilde{v}\right]
$$

where:

$\tilde{S} \equiv S+\left(\tilde{v} / k^{2} d^{2}\right) f v_{2}$ and $f_{v 2}=1-x / 1+x f_{v 1}$

$C_{b 1}$ and $\mathrm{k}$ are constants,

$\mathrm{d}$ is the distance from the wall and

$\mathrm{S}$ is a scalar measure of the deformation tensor.

The destruction term is modelled as:

Where:

$$
Y_{v}=C_{\omega 1} \rho f_{\omega}(\tilde{v} / d)^{2}
$$

$$
\left[f_{\omega}=\mathrm{g}\left[1+C \omega_{3}{ }^{6} / \mathrm{g}^{6}+C \omega_{3}{ }^{6}\right]^{1 / 6}, \mathrm{~g}=\mathrm{r}+C_{\omega 2}\left(r^{6}-r\right) \text { and } r \equiv \tilde{v} / \tilde{S} k^{2} d^{2}\right]
$$

$C_{\omega 1}, C_{\omega 2}$ and $C_{\omega 3}$ are constants.

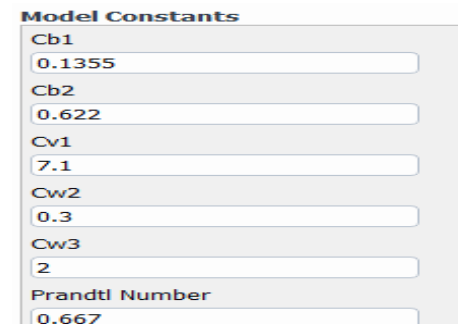

\section{k- $\varepsilon$ Standard Model}

This model depends upon transport equations for the turbulence kinetic energy $(\mathrm{k})$ and dissipation rate $(\boldsymbol{\varepsilon})$.

The assumptions made for the flow are turbulent and effects of molecular viscosity are negligible. Therefore, this model is suitable only for turbulent models.

The turbulence kinetic energy $\mathrm{k}$ and dissipation rate can form as follows:

$\left[\partial / \partial t(\rho k)+\partial / \partial x_{i}\left(\rho k u_{i}\right)=\partial / \partial x_{j}\left[\left(\mu+\mu_{t} / \sigma_{k}\right) \partial k / \partial x_{j}\right]+G_{k}+G_{b}-\rho_{\varepsilon}-Y_{M}+S_{k}\right]$.

$\left[\partial / \partial t(\rho \varepsilon)+\partial / \partial x_{i}\left(\rho \varepsilon u_{i}\right)=\partial / \partial x_{j}\left[\left(\mu+\mu t / \sigma_{\varepsilon}\right) \partial \varepsilon / \partial x_{j}\right]+C_{1 \varepsilon} \varepsilon / k\left(G_{k}+C_{3 \varepsilon} G_{b}\right)-C_{2 \varepsilon} \rho \varepsilon^{2} / k+S_{\varepsilon}\right]$

Where

$\mathrm{G}_{\mathrm{k}}$ - is the generation of turbulence kinetic energy, 
$\mathrm{G}_{\mathrm{b}-\mathrm{means}}$ the generation of turbulence kinetic energy,

$\mathrm{Y}_{\mathrm{m}}$ is the contribution of the fluctuating dilatation on compressible turbulence to all dissipation rate, $G_{1 \varepsilon}, G_{2 \varepsilon}$ and $C_{3 \varepsilon}$ are constants,

$\sigma_{k}$ and $\sigma_{\varepsilon}$ are the turbulent Prandtl numbers for $\mathrm{k}$ and $\varepsilon$,

$S_{k}$ and $S_{\varepsilon}$ are the terms for source.

$\mu_{t}=\rho C_{\mu} k^{2} / \varepsilon ; \mu t$ is turbulent viscosity, $C_{\mu}$ is constant

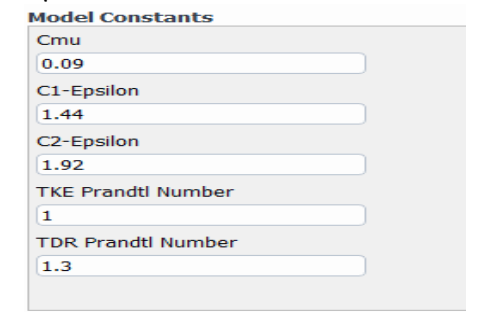

\section{k- $\omega$ Standard Model}

The standard empirical model that depends on the model transport equations for the turbulence kinetic equation and specific dissipation rate.

The transport equations of turbulence kinetic energy and the specific dissipation rate are derived below

$$
\begin{gathered}
{\left[\partial / \partial t(\rho k)+\partial / \partial x_{i}\left(\rho k u_{i}\right)=\partial / \partial x_{j}\left(\Gamma_{k} \partial k / \partial x_{j}\right)+G_{k}-Y_{k}+S_{k}\right] \ldots \ldots} \\
{\left[\partial / \partial t(\rho \omega)+\partial / \partial x_{i}\left(\rho \omega u_{i}\right)=\partial / \partial x_{j}\left(\Gamma_{\omega} \partial \omega / \partial x_{j}\right)+G_{\omega}-Y_{\omega}+S_{\omega}\right] .}
\end{gathered}
$$

The effective diffusivities for the k- $\omega$ model are described as:

$$
\left[\Gamma_{k}=\mu+\mu_{t} / \sigma_{k} \text { and } \Gamma_{\omega}=\mu+\mu_{t} / \sigma_{\omega}\right]
$$

Where,

$\sigma_{k}$ and $\sigma_{\omega}$ are the turbulent Prandtl numbers for k and $\omega$, respectively.

The result of turbulent viscosity $\mu_{t}$ is produced by combining $\mathrm{k}$ and $\omega$ as follows:

$$
\left[\mu_{t}=\alpha * \rho k \omega\right]
$$

The production of turbulence kinetic energy $G_{k}$ maybe given by:

$$
\left[G_{k}=-\rho u_{i}{ }^{\prime} u_{j}{ }^{\prime} \partial u_{j} / \partial x_{i}\right]
$$

To evaluate $G_{k}$ in a manner consistent with the Boussinesq hypothesis: $G_{k}=\mu_{t} S^{2}$. The production of $\omega$ is given by:

$$
G_{\omega}=\alpha(\omega / k) G k
$$

The dissipation of $\mathrm{k}$ is giving by:

$$
Y_{k}=\rho \beta * f_{\beta} * k \omega .
$$

The dissipation of $\omega$ is giving by:

$$
Y_{\omega}=\rho \beta * f_{\beta} \omega^{2}
$$

$Y_{k}$ and $Y_{\omega}$ are the dissipations of $\mathrm{k}$ and $\omega$, and defined identically as in the standard k- $\omega$ model. 


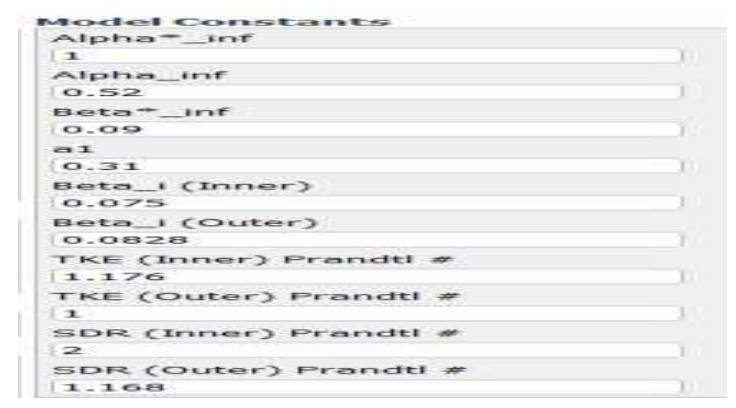

\subsection{BOUNDARY CONDITIONS}

The assumptions made for the flow are Laminar, Incompressible, steady and 2-Dimensional. The outlet domain is set be pressure-outlet and gauge pressure are zero.

TABLE-1 Boundary conditions at $V=12.5 \mathrm{~m} / \mathrm{s}$

TABLE-2 Boundary conditions at $V=14.5 \mathrm{~m} / \mathrm{s}$

\begin{tabular}{|l|l|}
\hline Dynamic viscosity $(\boldsymbol{\mu})$ & $\begin{array}{l}\mathbf{1 . 8 1} \times \mathbf{1 0} \\
\mathbf{5} \mathbf{~ k g} /(\mathbf{m} \cdot \mathbf{s})\end{array}$ \\
\hline Density & $1.23 \mathrm{Kg} / \mathrm{m} 3$ \\
\hline Inflow velocity $(U \infty)$ & $12.5 \mathrm{~m} / \mathrm{s}$ \\
\hline Reynolds number & 127417.1271 \\
\hline
\end{tabular}

\begin{tabular}{|l|l|}
\hline Dynamic viscosity $(\boldsymbol{\mu})$ & $\begin{array}{l}\mathbf{1 . 8 1} \times \mathbf{1 0} \\
\mathbf{5} \mathbf{~ k g} /(\mathbf{m} \cdot \mathbf{s})\end{array}$ \\
\hline Density & $1.23 \mathrm{Kg} / \mathrm{m} 3$ \\
\hline Inflow velocity $(U \infty)$ & $14.5 \mathrm{~m} / \mathrm{s}$ \\
\hline Reynolds number & 147803.8674 \\
\hline
\end{tabular}

\section{III.RESULTS AND DISCUSSION}

This section gives the info about the numerical simulation results for the aerodynamic performance of the Morphing trailing edge of NACA0015 at velocities $12.5 \mathrm{~m} / \mathrm{s}$ and $14.5 \mathrm{~m} / \mathrm{s}$.

\subsection{Aerodynamic performance analysis during MTE}

To study the influence of Angle of $\operatorname{attack}(\alpha)$ and Deflection $(\theta)$ on the aerodynamic characteristics of Morphing trailing edge (MTE), the 5 air foils listed in fig- 1 were simulated. The deflection angles of the 5 air foils are measured as $0^{0}, 2^{0}, 5^{0}, 7^{0}, 9^{0}$. The range of $\alpha$ is set be $0^{0}$ to $20^{0}$ with interval $2^{0}$. The Mach number and Reynolds numbers at $12.5 \mathrm{~m} / \mathrm{s}$ are 0.21 and 127417.1271 and at $14.5 \mathrm{~m} / \mathrm{s}$ are 0.25 and 147803.8674 .

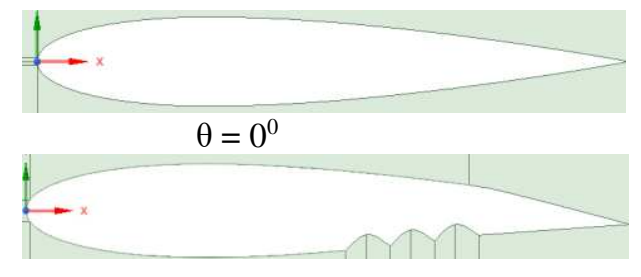

$\theta=5^{0}$
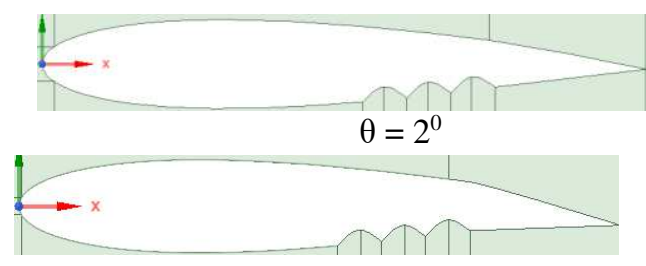

$\theta=7^{0}$

$\theta=9^{0}$

figure -1 
Figure 2: shows the simulation results of the 5 stable states of the Morphing at $12.5 \mathrm{~m} / \mathrm{s}$ and $14.5 \mathrm{~m} / \mathrm{s}$.

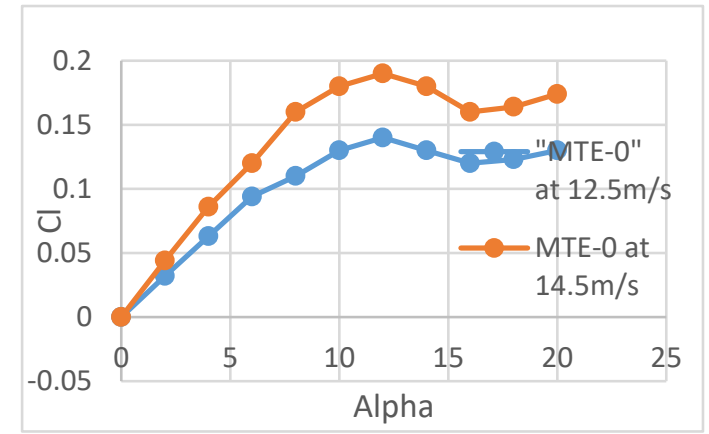

Figure-2(a) $\theta=0^{0}$, Velocity $=12.5 \mathrm{~m} / \mathrm{s}$

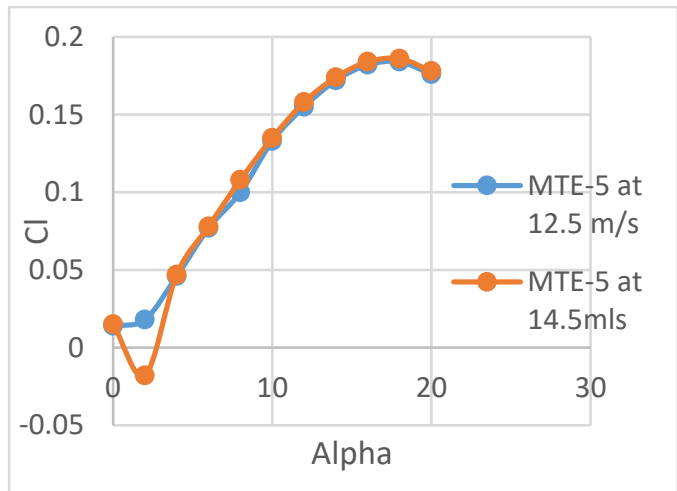

Figure-2(c) $\theta=5^{0}$

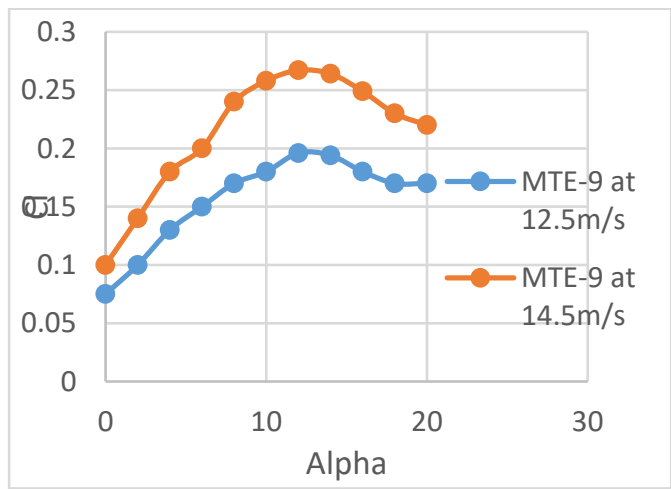

Figure-2(e) $\theta=9^{0}$

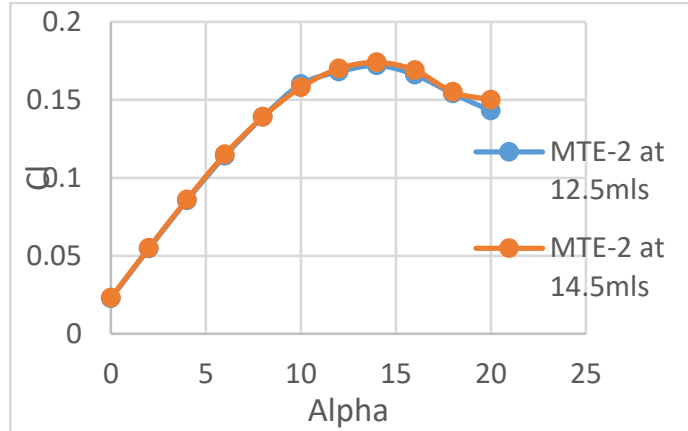

Figure -2 (b) $\theta=2^{0}$, Velocity $=14.5 \mathrm{~m} / \mathrm{s}$

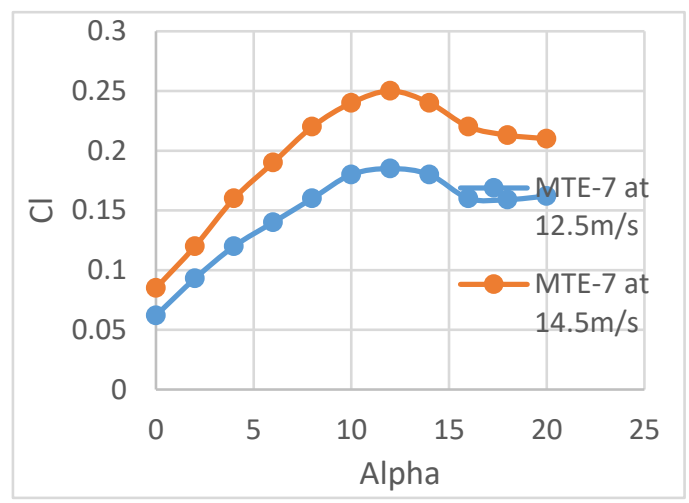

Figure-2(d) $\theta=7^{0}$

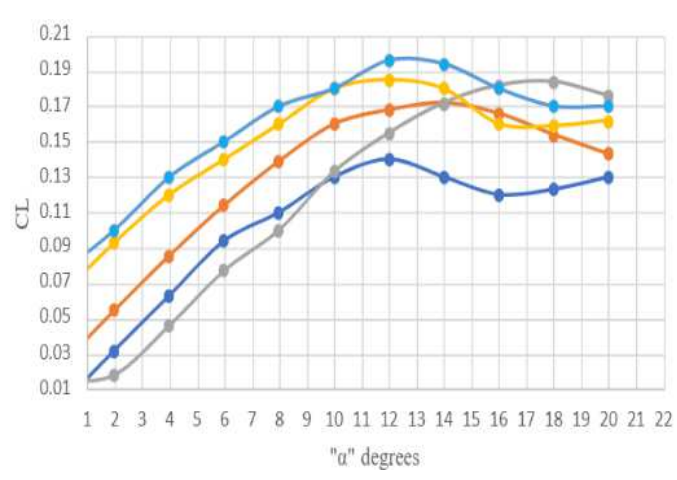

Fig- 2(f) $\mathrm{C}_{\mathrm{L}}$ Combined graph 


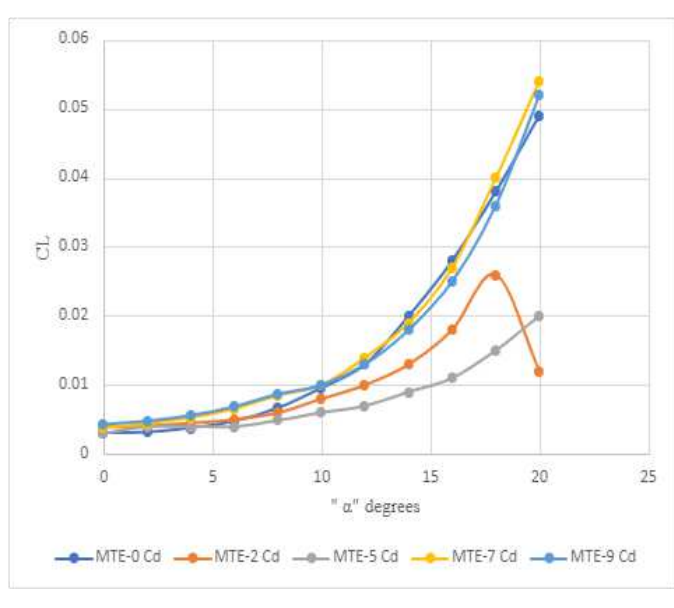

Fig $2(\mathrm{~g}) \mathrm{C}_{\mathrm{D}}$ Combined graph

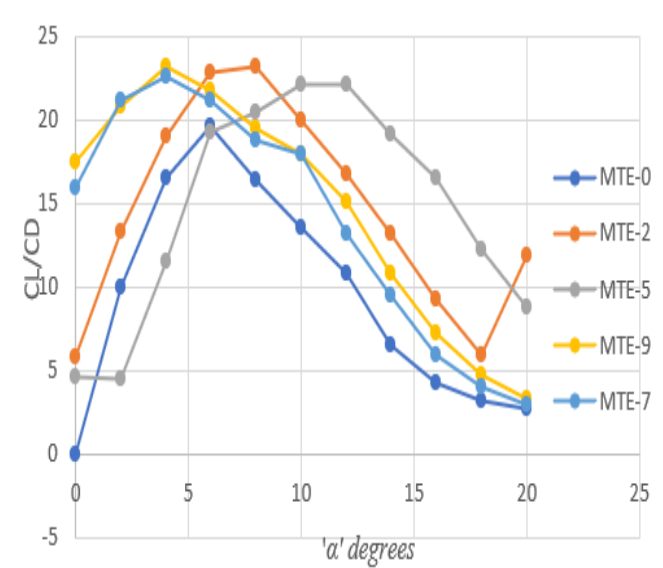

Fig-2(h) $C_{L} / C_{D}$ Combined graph

The $\mathrm{C}_{\mathrm{L}}$ vs $\alpha$ graph results in morphing trailing edge depicted in the above fig- 2 are used for evaluating the aerodynamic performance.

In Fig.2(a) Deflection $\theta=0^{0}$ at velocity $12.5 \mathrm{~m} / \mathrm{s}$ and $14.5 \mathrm{~m} / \mathrm{s}$, the maximum coefficient of lift occurs at $12^{0}$ angle of attack (AOA), there the flow get separated. Here, $\mathrm{C}_{\mathrm{L} \text { max }}$ difference is around $5 \%$.

In Fig 2(b) Deflection $\theta=2^{0}$ the maximum coefficient of lift at velocities $12.5 \mathrm{~m} / \mathrm{s}$ and $14.5 \mathrm{~m} / \mathrm{s}$ occurs at AOA $14^{0}$.The maximum coefficient of lift between the two velocities is about $2 \%$.

In Fig.2(c) Deflection $\theta=5^{0}$ at angle of attack $18^{0}$ the maximum coefficient of lift occurs with the velocity $12.5 \mathrm{~m} / \mathrm{s}$ and $14.5 \mathrm{~m} / \mathrm{s}$. $\mathrm{C}_{\mathrm{L} \text { max }}$ difference is about $2 \%$.

In Fig.2(d) Deflection $\theta=7^{0}$ at velocity $12.5 \mathrm{~m} / \mathrm{s}$ the maximum coefficient lift occurs at $14^{0}$ angle of attack, whereas at $14.5 \mathrm{~m} / \mathrm{s}$ velocity it occurs at $12^{\circ}$ angle of attack.The maximum coefficient of lift between the two velocities is about $7 \%$, the value has increased.

In Fig.2(e) Deflection $\theta=9^{0}$ the maximum coefficient of lift at velocity $12.5 \mathrm{~m} / \mathrm{s}$ and $14.5 \mathrm{~m} / \mathrm{s}$ occurs at $12^{0}$ angle of attack. $\mathrm{C}_{\mathrm{L} \max }$ difference is around $7.1 \%$.

TABLE - $3 \mathrm{C}_{\mathrm{L}}$ AND $\mathrm{C}_{\mathrm{D}}$ VALUES WITH RESPECT TO $\alpha$ AT VELOCITY $12.5 \mathrm{~m} / \mathrm{s}$

\begin{tabular}{|c|c|c|c|c|c|c|c|c|c|c|}
\hline & \multicolumn{2}{|c|}{ Case-0-Without MTE } & \multirow{2}{*}{\multicolumn{2}{|c|}{$\begin{array}{l}\text { Case-1- MTE-2deg } \\
\text { velocity at } 12.5 \mathrm{~m} / \mathrm{s}\end{array}$}} & \multirow{2}{*}{\multicolumn{2}{|c|}{$\begin{array}{l}\text { Case-2- MTE-5deg } \\
\text { velocity at } 12.5 \mathrm{~m} / \mathrm{s}\end{array}$}} & \multirow{2}{*}{\multicolumn{2}{|c|}{$\begin{array}{l}\text { Case-3- MTE-7deg } \\
\text { velocity at } 12.5 \mathrm{~m} / \mathrm{s}\end{array}$}} & \multirow{2}{*}{\multicolumn{2}{|c|}{$\begin{array}{l}\text { Case-4- MTE-9deg } \\
\text { velocity at } 12.5 \mathrm{~m} / \mathrm{s}\end{array}$}} \\
\hline \multicolumn{3}{|c|}{ velocity at $12.5 \mathrm{~m} / \mathrm{s}$} & & & & & & & & \\
\hline \begin{tabular}{l|l}
$O A$ \\
\end{tabular} & $\mathrm{Cl}$ & $\mathrm{Cd}$ & $\mathrm{Cl}$ & $\mathrm{Cd}$ & $\mathrm{Cl}$ & $\mathrm{Cd}$ & \multicolumn{2}{|c|}{\begin{tabular}{l|l}
$\mathrm{Cl}$ & $\mathrm{Cd}$
\end{tabular}} & \begin{tabular}{l|l}
$\mathrm{Cl}$ & $\mathrm{C}$ \\
\end{tabular} & $\mathrm{Cd}$ \\
\hline 0 & $-1 \mathrm{E}-06$ & 0.00313 & 0.0226 & 0.0039 & 0.014 & 0.003 & 0.062 & 0.0039 & 0.075 & 0.0043 \\
\hline 2 & 0.032 & 0.0032 & 0.0546 & 0.0041 & -0.018 & 0.004 & 0.093 & .0044 & 0.1 & 0048 \\
\hline 4 & & 38 & & 0.0045 & 46 & 0.004 & .12 & 0053 & .13 & 005 \\
\hline 6 & & & & & 077 & 0.004 & 14 & 666 & 15 & 06 \\
\hline 8 & & & & & 0.1 & 0.0049 & 0.16 & 0.0085 & 17 & 0.0087 \\
\hline 10 & & 0.0096 & & 0.008 & 33 & 0.006 & 0.18 & 0.01 & 0.18 & 0.01 \\
\hline 12 & & 0.013 & & 0.01 & 55 & 0.007 & 0.185 & 0.014 & 0.196 & .013 \\
\hline 14 & & 0.02 & & 0.013 & 72 & 0.009 & 0.18 & 0.019 & 0.194 & .018 \\
\hline 16 & & 0.028 & & 0.018 & 182 & 0.011 & 0.16 & 0.027 & 0.18 & 0.025 \\
\hline 18 & 0.12 & 0.038 & & 0.026 & 184 & 0.015 & 0.159 & 0.04 & 0.17 & 0.03 \\
\hline 20 & 0.13 & 0.049 & 0.143 & 0.012 & 0.176 & 0.02 & 0.162 & 0.054 & 0.17 & 0.05 \\
\hline
\end{tabular}




\begin{tabular}{|c|c|c|c|c|c|c|c|c|c|c|}
\hline \multicolumn{3}{|c|}{ Case-4- MTE-9deg } & \multicolumn{2}{|c|}{ Case-3- MTE-7deg } & \multicolumn{2}{|c|}{ Case-2- MTE-5 deg } & \multicolumn{2}{|c|}{ Case-1- MTE-2deg } & \multicolumn{2}{|c|}{ Case-0- Without MTE } \\
\hline \multicolumn{3}{|c|}{ velocity at $14.5 \mathrm{~m} / \mathrm{s}$} & \multicolumn{2}{|c|}{ velocity at $14.5 \mathrm{~m} / \mathrm{s}$} & \multicolumn{2}{|c|}{ velocity at $14.5 \mathrm{~m} / \mathrm{s}$} & \multicolumn{2}{|c|}{ velocity at $14.5 \mathrm{~m} / \mathrm{s}$} & \multicolumn{2}{|c|}{ velocity at $14.5 \mathrm{~m} / \mathrm{s}$} \\
\hline $\mathrm{AOA}$ & $\mathrm{Cl}$ & $\mathrm{Cd}$ & $\mathrm{Cl}$ & $\mathrm{Cd}$ & $\mathrm{Cl}$ & $\mathrm{Cd}$ & $\mathrm{Cl}$ & $\mathrm{Cd}$ & $\mathrm{Cl}$ & $\mathrm{Cd}$ \\
\hline 0 & 0.1 & 0.0054 & 0.085 & 0.0052 & 0.015 & 0.003 & 0.023 & 0.003 & -0.0000018 & 0.004 \\
\hline 2 & 0.14 & 0.0061 & 0.12 & 0.0058 & -0.018 & 0.003 & 0.055 & 0.003 & 0.044 & 0.0042 \\
\hline 4 & 0.18 & 0.0072 & 0.16 & 0.007 & 0.047 & 0.003 & 0.086 & 0.004 & 0.086 & 0.0049 \\
\hline 6 & 0.2 & 0.0089 & 0.19 & 0.0087 & 0.078 & 0.004 & 0.115 & 0.005 & 0.12 & 0.0063 \\
\hline 8 & 0.24 & 0.011 & 0.22 & 0.011 & 0.108 & 0.0047 & 0.139 & 0.006 & 0.16 & 0.0089 \\
\hline 10 & 0.258 & 0.014 & 0.24 & 0.014 & 0.135 & 0.005 & 0.158 & 0.008 & 0.18 & 0.012 \\
\hline 12 & 0.267 & 0.018 & 0.25 & 0.019 & 0.158 & 0.007 & 0.17 & 0.017 & 0.19 & 0.018 \\
\hline 14 & 0.264 & 0.023 & 0.24 & 0.025 & 0.174 & 0.008 & 0.174 & 0.013 & 0.18 & 0.027 \\
\hline 16 & 0.249 & 0.033 & 0.22 & 0.037 & 0.184 & 0.011 & 0.169 & 0.017 & 0.16 & 0.038 \\
\hline 18 & 0.23 & 0.048 & 0.213 & 0.054 & 0.186 & 0.014 & 0.155 & 0.002 & 0.164 & 0.0511 \\
\hline 20 & 0.22 & 0.07 & 0.21 & 0.074 & 0.178 & 0.019 & 0.15 & 0.003 & 0.174 & 0.067 \\
\hline
\end{tabular}

\subsection{Flow field Analysis}

As shown in fig-3 the pressure contours of 5 deflections at $12.5 \mathrm{~m} / \mathrm{s}$ and $14.5 \mathrm{~m} / \mathrm{s}$. The maxima and minima pressure on the airfoils is verified by the intensity of the colour. The pressure beneath the airfoil is darker, it means there is an increase of $C_{L}$ when the deflection is increasing. From all the pressure contours, $9^{0}$ deflection has maximum $C_{p}$ on the basis of intensity of colour beneath the airfoil. As, the increase in deflection the $C_{p}$ is also getting increased, $C_{L}$ values are also getting increased.

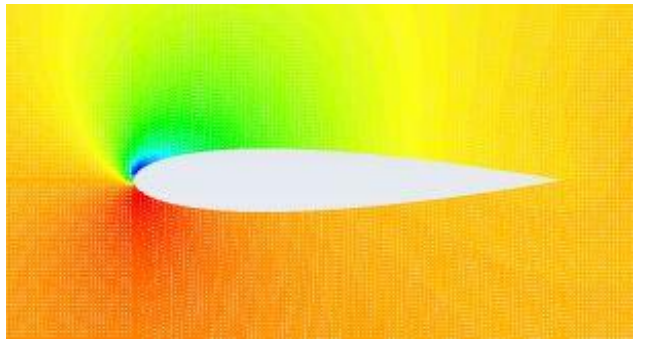

Figure-3(a) $\theta=0^{0}, \alpha=12^{0}$ at $12.5 \mathrm{~m} / \mathrm{s}$

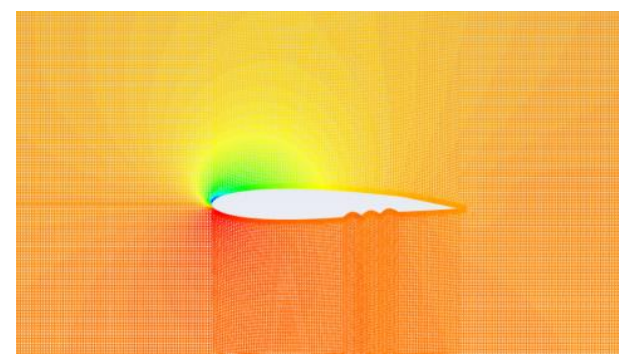

Figure-3(c) $\theta=2^{0}, \alpha=12^{0}$ at $12.5 \mathrm{~m} / \mathrm{s}$

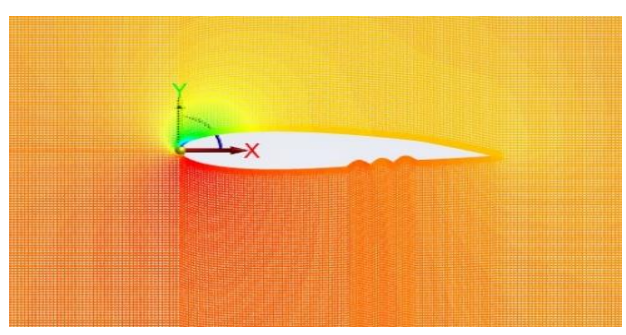

Figure-3(e) $\theta=5^{0}, \alpha=18^{0}$ at $12.5 \mathrm{~m} / \mathrm{s}$

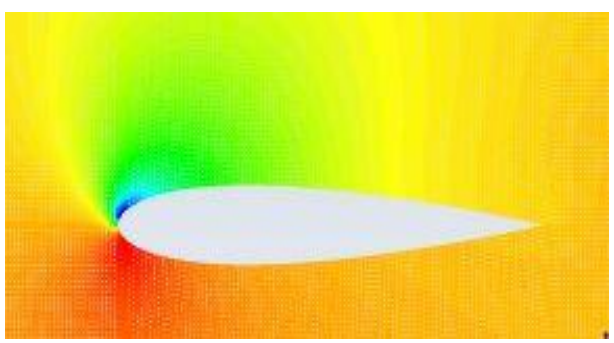

Figure-3(b) $\theta=0^{0}, \alpha=12^{0}$ at $14.5 \mathrm{~m} / \mathrm{s}$

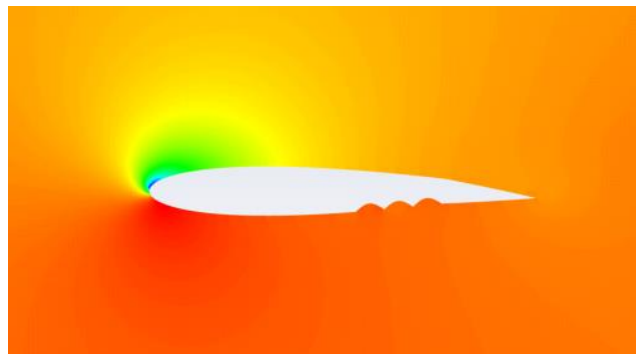

Figure-3(d) $\theta=2^{0}, \alpha=14^{0}$ at $14.5 \mathrm{~m} / \mathrm{s}$

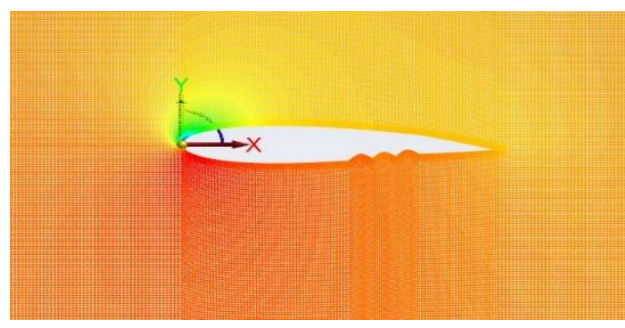

Figure-3(f) $\theta=5^{0}, \alpha=18^{0}$ at $14.5 \mathrm{~m} / \mathrm{s}$ 


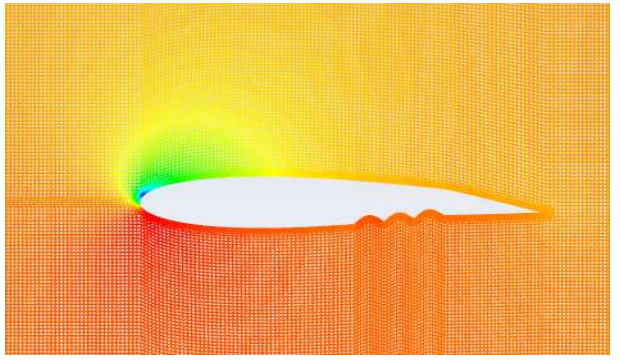

Figure-3(g) $\theta=7^{0}, \alpha=14^{0}$ at $12.5 \mathrm{~m} / \mathrm{s}$

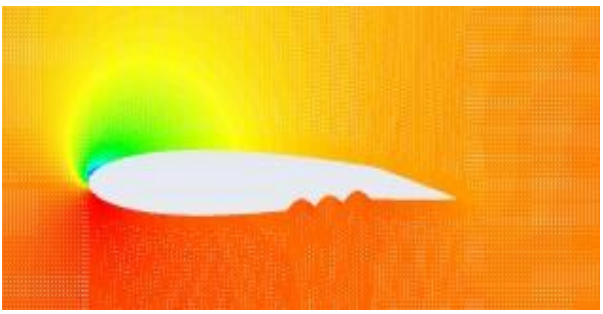

Fig-3(i) $\theta=9^{0}, \alpha=12^{0}$ at $12.5 \mathrm{~m} / \mathrm{s}$

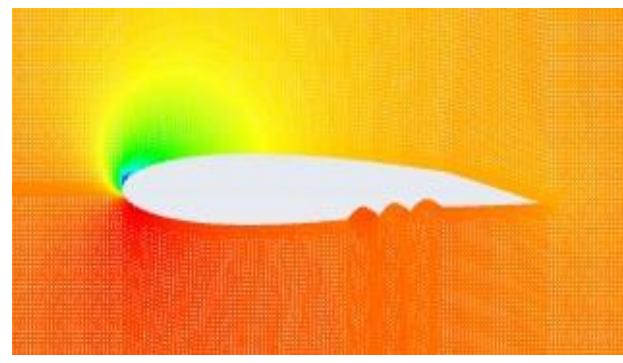

Figure-3(h) $\theta=7^{0}, \alpha=12^{0}$ at $14.5 \mathrm{~m} / \mathrm{s}$

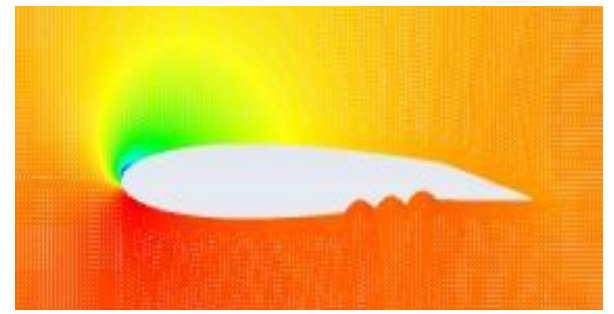

Fig-3(j) $\theta=9^{0}, \alpha=12^{0}$ at $14.5 \mathrm{~m} / \mathrm{s}$

\section{Velocity Contours-}

As shown in fig-4 the velocity contours of 5 deflections at $12.5 \mathrm{~m} / \mathrm{s}$ and $14.5 \mathrm{~m} / \mathrm{s}$. From the analysis, for $0^{0}, 7^{0}, 9^{0}$ the flow gets separated at the AOA $12^{0}$, for $2^{0}$ deflection the flow gets separated at the AOA $14^{0}$ and for $5^{0}$ deflection the flow gets separated at $18^{0}$ at $12.5 \mathrm{~m} / \mathrm{s}$. Therefore, the above results shows that $5^{0}$ deflection is suitable for takeoff for MAVs in case of $12.5 \mathrm{~m} / \mathrm{s}$.

For $14.5 \mathrm{~m} / \mathrm{s}$ velocity, At $\theta=0^{0}, 7^{0}, 9^{0}$ the flow gets separated at $12^{0}$ AOA, $\theta=2^{0}$ flow gets separated at $14^{0}, \theta=5^{0}$ flow gets separated at $18^{0}$.

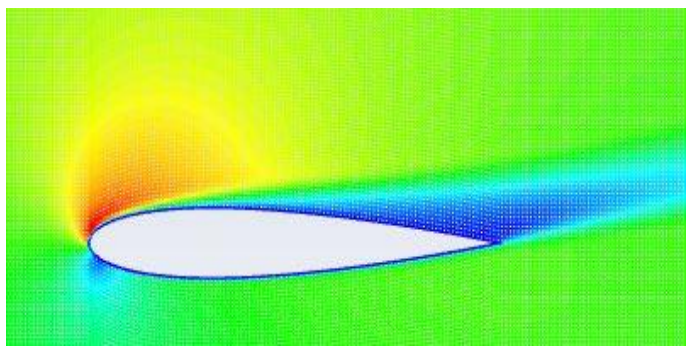

Figure-4(a) $\theta=0^{0}, \alpha=12^{0}$ at $12.5 \mathrm{~m} / \mathrm{s}$

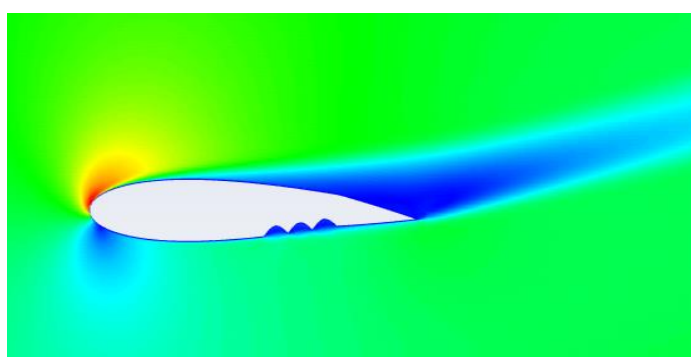

Figure-4(c) $\theta=2^{0}, \alpha=12^{0}$ at $12.5 \mathrm{~m} / \mathrm{s}$

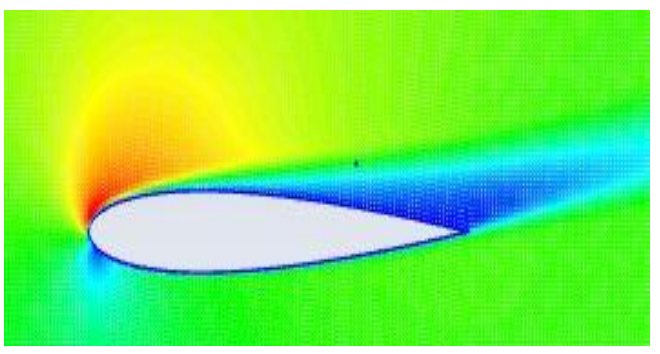

Figure-4(b) $\theta=0^{0}, \alpha=12^{0}$ at $14.5 \mathrm{~m} / \mathrm{s}$

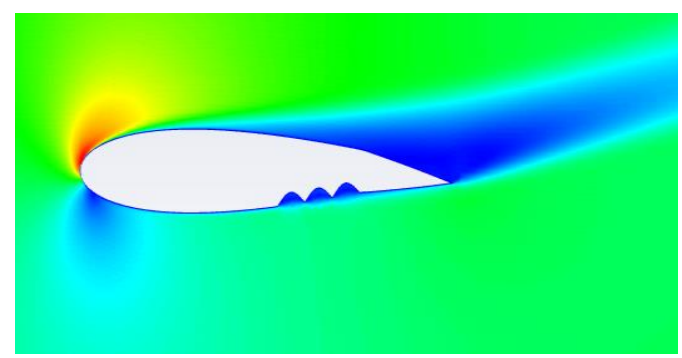

Figure-4(d) $\theta=2^{0}, \alpha=14^{0}$ at $14.5 \mathrm{~m} / \mathrm{s}$ 


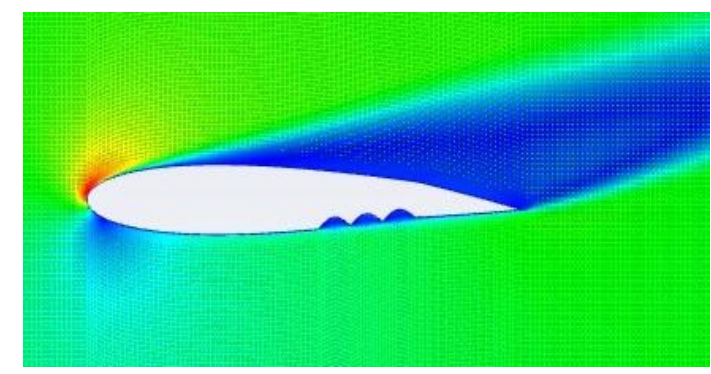

Figure-4(c) $\theta=5^{0}, \alpha=18^{0}$ at $12.5 \mathrm{~m} / \mathrm{s}$

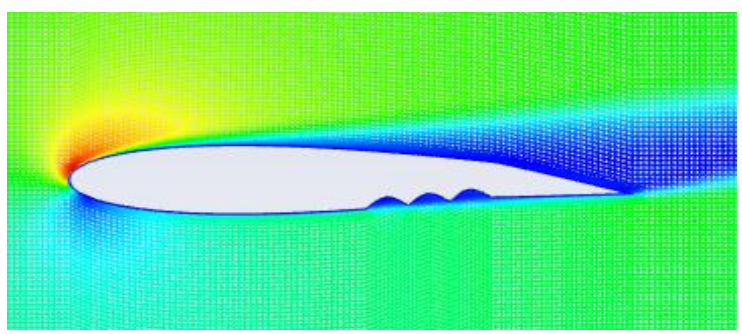

Figure-4(e) $\theta=7^{0}, \alpha=14^{0}$ at $12.5 \mathrm{~m} / \mathrm{s}$

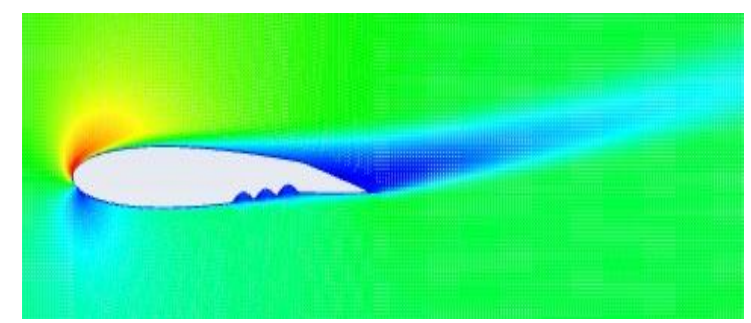

Figure $-4(\mathrm{~g}) \quad \theta=9^{0}, \alpha=12^{0}$ at $12.5 \mathrm{~m} / \mathrm{s}$

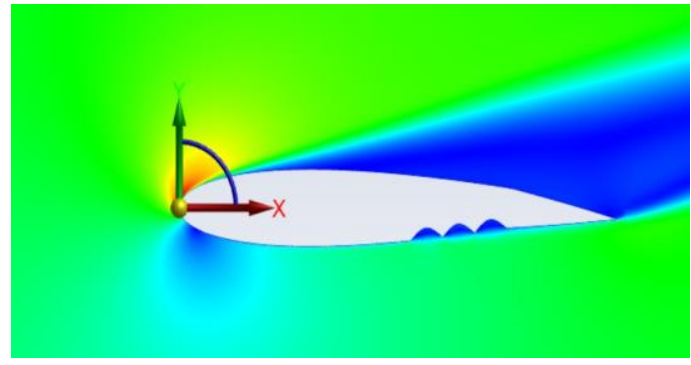

Figure-4(d) $\theta=5^{0}, \alpha=18^{0}$ at $14.5 \mathrm{~m} / \mathrm{s}$

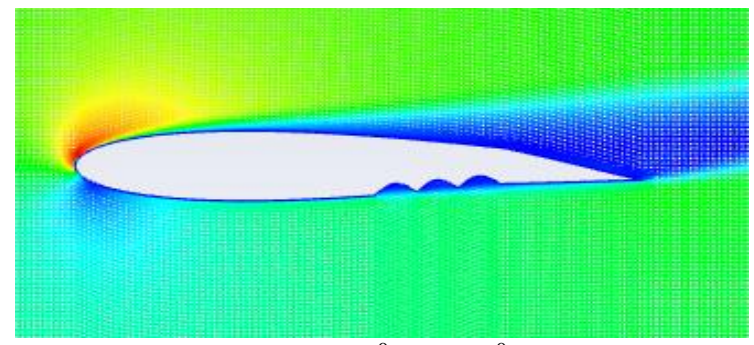

Figure-4(f) $\theta=7^{0}, \alpha=12^{0}$ at $14.5 \mathrm{~m} / \mathrm{s}$

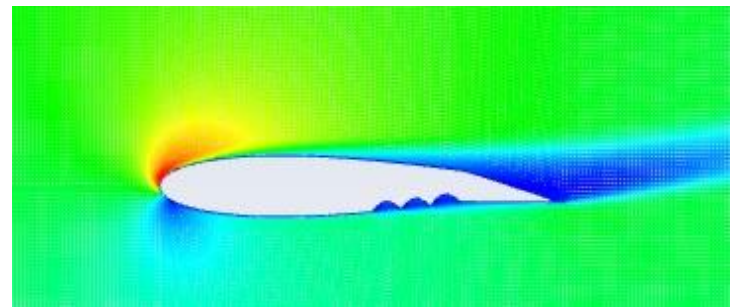

Figure $-4(\mathrm{~h}) \theta=9^{0}, \alpha=12^{0}$ at $14.5 \mathrm{~m} / \mathrm{s}$

\section{CONCLUSIONS}

- Since the first week of confirming of topic chosen, research has been done through journals and reference books in internet and library. Lift is found to be the most important aerodynamic parameter for flight.

- Numerical flow analysis has been done for morphing airfoil with required boundary conditions and using flow models.

- The improved design Corrugated morphed trailing edge - performed much better in higher lift and lower drag as compared without morphing NACA0015 at different Angles of Attacks (AOA).

- By comparing graph $\mathrm{C}_{\mathrm{L}}$ and $\mathrm{C}_{\mathrm{D}}$ versus $\mathrm{AOA}$ at different deflections (i.e, $0^{0}, 2^{0}, 5^{0}, 7^{0}$, $\left.9^{0}\right)$ it shows as deflection is increasing, the $\mathrm{C}_{\mathrm{L}}$ is also increasing.

- But, from all the results, it is observed that for take-off at $\theta=50$ (deflection) suitable. As, the flow is separating at $18^{0} \mathrm{AOA}$. 


\section{Observations:}

- From all the results, aerodynamic efficiency has improved. The design objective is to increase the Lift-to-Drag ratio while take-off and Cruise.

- For take-off $5^{0}$ deflection is suitable. Because it delays the flow till $18^{0}$ AOA.Morphing trailing edge concept designed and numerically analyzed in this work.

- This work has been done for steady model characteristics of aerodynamics with different various conditions alpha and deflections between corrugated without morphing and with morphing.

- The corrugated shape introduced to help for mechanism in future geometries. By increasing of (theta)deflection the $\mathrm{cl}$ and cd increases accordingly varying with angle of attack (alpha). When increasing at small alpha in different flights conditions then MTE provides to enhance the lift in a flight condition i.e., during takeoff and cruise.

- The MTE concept has increased performance compare to without MTE morphing and as well as increases CL and reducing drag in different deflection of MTE, therefor at same flight conditions, the overall aerodynamic efficiency of MTE is improved than the without corrugated.

- At stall point due to MTE it suppresses the flow separation and reduces the vortices, there is more advantage in large deflection conditions.

- The project will be continued by fabricating the 2-dimensional models using $3 \mathrm{~d}$ printing and testing has been done by using Low Speed Subsonic Wind-tunnel.

\section{V.ACKNOWLEDGEMENT}

The authors acknowledge the support of GITAM School of Technology of Hyderabad. This work is supported by Aerospace Department of GITAM Deemed to be University Hyderabad.

\section{References -}

1. Zi KAN, Daochun LI, Tong SHEN, Jinwu XIANG, Lu ZHANG ‘Aerodynamic characteristics of morphing wing with flexible leading-edge'

2. Comparative Study on the Prediction of Aerodynamic Characteristics of Mini Unmanned Aerial Vehicle with Turbulence Models Soma Shekar, Immanuel Selwyn Raj.

3. https://www.researchgate.net/publication/304490025_Introduction_to_micro_air_vehicles_co ncepts_design_and_applications 'Introduction to micro air vehicles: concepts, design and applications' 
4. https://en.wikipedia.org/wiki/Micro_air_vehicle

5. Comparative-Study-on-the-Prediction-of-Aerodynamic-Jang

\section{Availability of data and materials}

All data generated or analyzed during this study are included in this published article with appropriated citations.

\section{Acknowledgements}

The authors would like to thank the Computation Laboratory in Department of Aerospace Engineering for providing the laboratory and the necessary equipment to carry out the required work.

Funding

No funding

\section{Author information}

\section{Affiliations}

Department of Aerospace Engineering, GITAM (Deemed to be University), Hyderabad, 502329, India

Mr. S. Kishore Kumar ${ }^{1 *}$, Kanneti Nithisha ${ }^{2}$, Manvi Vivek ${ }^{3}$ and Mohammad Saniya Simran $^{4}$, Dr. Ravi Sri Raman ${ }^{5}$

\section{Contributions}

The contribution of the authors to this work is equivalent. All authors read and approved the final manuscript.

\section{Corresponding author}

Correspondence to $\underline{S}$ Kishore Kumar.

Ethics declarations

\section{Competing interests}

The authors declare that they have no competing interests. 
